\title{
Organic Solvents
}

National Cancer Institute

\section{Source}

National Cancer Institute. Organic Solvents. NCI Thesaurus. Code C1737.

A group of org anic liquid compounds that are used for extracting, dissolving, or suspending other water insoluble compounds. $(\mathrm{NCl})$ 